\title{
Emergency department airway management in the UK
}

\author{
Colin A Graham MPH FFAEM
}

Management of the compromised airway in UK emergency departments has changed greatly over the past decade. This paper examines the roles of emergency physicians and anaesthetists and the way that advanced airway management in this setting is likely to evolve over the next ten years.

\section{HISTORY}

Since 1975, when higher specialist training in accident and emergency medicine was established in the UK, ${ }^{1}$ specialist trainees have been required to undertake a three-month secondment (minimum) in anaesthesia and intensive care medicine. At the inception of higher training, most trainees came from a surgical background; there were just a few physicians, paediatricians and anaesthetists.

The aims of this secondment were to orientate trainees to the basic concepts of general anaesthesia and to train them in airway management skills, including intubation. It was not generally expected that higher specialist trainees would become competent in the use of anaesthetic or neuromuscular blocking drugs within those three months; there seemed no likelihood that drug-assisted airway manoeuvres would ever be performed by emergency department staff without the input of an anaesthetist. ${ }^{2}$

However, during the 1980s, attitudes began to change and several emergency departments - notably that at the Royal Infirmary of Edinburgh - began to use advanced airway techniques including rapid sequence intubation (RSI). ${ }^{3}$ In Edinburgh, pre-hospital RSI also became a regularly used technique on the Medic 1 flying squad. ${ }^{4}$ The minimum training requirement remained three months in anaesthesia and intensive care medicine, ${ }^{5}$ but many trainees were voluntarily undertaking longer periods in anaesthesia.

The 1998 Faculty of Accident and Emergency Medicine meeting at Oxford provided data from the USA indicating that emergency physicians could manage the emergency airway with a similar complication rate to that of anaesthetists. ${ }^{6}$ Walls from Boston had devised the National Emergency Airway Registry (NEAR), which continues to collect data. 7,8 Walls suggested that formal training for emergency physicians in airway management could be accomplished by use of the NEAR course, ${ }^{6}$ which offers training in all aspects of emergency airway care.

Accident and Emergency Medicine Academic Unit, Chinese University of Hong Kong, Trauma and Emergency Centre, Prince of Wales Hospital, Shatin, New Territories, Hong Kong

E-mail: cagraham@cuhk.edu.hk
There have been repeated calls for improvements in the airway training of UK emergency physicians. Gwinnutt proposed the use of anaesthesia senior house officer posts to enhance the education of trainees. ${ }^{2}$ This might provide a more seamless interface between the emergency department and critical care areas. ${ }^{9}$ Nolan and Clancy suggested that all trainees should have six months in anaesthesia and six months in critical care. ${ }^{10}$

\section{PRACTICE TODAY}

In 2000, Walker and Brenchley surveyed consultant anaesthetists and consultant emergency physicians in large UK hospitals about the use of RSI techniques in emergency departments (response rate $72 \%$ ). ${ }^{11}$ In several hospitals emergency physicians were using these techniques routinely, and two-thirds of the anaesthetists had no objection provided they were adequately trained. Also in 2000, Graham et al. reported a survey of senior and middle grade emergency department staff in seven teaching hospitals in Scotland (response rate $78 \%$ ). ${ }^{12} 98 \%$ had a reasonable, high or very high degree of self-rated confidence in assessing a potentially difficult airway before intubation. $79 \%$ of the respondents had the same level of self-rated confidence in their ability to administer drugs to facilitate intubation. $47 \%$ had used drugs to facilitate intubation in the month before the survey. Consultants were more confident in their skills and had performed RSI more recently than other grades of staff. The possession of an anaesthetic qualification was associated with a high degree of confidence in performing RSI. Those with anaesthetic qualifications were also noted to have performed RSI more recently than those without. This study only looked at emergency department staff in Scottish teaching hospitals and the results cannot necessarily be extrapolated to other sorts of hospital or other parts of the UK.

\section{Clinical studies}

Butler et al. reported in 2001 on current practice in four English emergency medicine training programmes. ${ }^{13}$ This 28 -day observational study showed that $74 \%$ of decisions to undertake RSI were made by emergency physicians and over half the intubations occurred after $1600 \mathrm{~h}$. $26 \%$ of RSIs were performed by emergency physicians and the remainder by anaesthetists. In two-thirds of cases, the time taken from the decision to perform RSI to successful intubation was greater than twenty minutes. Six minor complications were recorded. These workers concluded that improvements 
could be made to patient care and that standards of care should be agreed for provision of RSI in the emergency department. Crucially, they also suggested that RSI in the emergency department should be audited nationally.

In 2003, Graham et al. reported on the Scottish RSI Project ${ }^{14}$ — a multicentre observational study that ran for two years in seven Scottish urban teaching hospitals, designed to capture data on every patient on whom intubation was attempted. Prospectively collected data were collected on 1631 patients, of whom 735 had RSI. The study showed that anaesthetists had a higher initial intubation success rate and obtained better views at laryngoscopy than emergency physicians. Patients intubated by emergency physicians had a somewhat higher proportion of patients who experienced immediate complications, though this did not reach statistical significance. Their rate of all complications was significantly higher, though comparable to that in another study of intubation in the critically ill. ${ }^{15}$ Part of this difference may be explained by the fact that the emergency physicians and anaesthetists were dealing with different sorts of patients. Emergency physicians performed RSI on more patients with physiological compromise and a higher proportion of these were intubated within fifteen minutes of arrival in the department. Patients in this category were probably so unwell that immediate intervention was required by the emergency physician in an effort to save life.

Both these observational studies indicated that UK emergency physicians safely administer drugs for airway management and perform RSI with an acceptable rate of complications - although there is clearly room for improvement. Like Butler et al., Graham et al. felt that there were roles for both emergency physicians and anaesthetists in the management of the acute airway and called for close collaboration for training and service delivery. ${ }^{14}$

\section{Failed intubation}

Part of the traditional anaesthesia approach when intubation fails is to 'wake the patient up' and allow the effects of any short-acting neuromuscular blocking drugs to wear off, with the resumption of spontaneous respiration. When an emergency airway is required in the resuscitation room, this approach may not be suitable and Carley et al. ${ }^{16}$ proposed an algorithm that includes rescue techniques such as the laryngeal mask airway and surgical techniques such as cricothyroidotomy. This emergency department algorithm is distinctly preferable to those devised for operating-room practice.

\section{Trauma patients}

Graham et al. matched patients from the RSI study to the national Scottish Trauma Audit Group (STAG) database to assess the relation between anaesthetist-intubated patients and emergency-physician-intubated patients in terms of anatomical and physiological derangement. ${ }^{17} 439$ trauma patients were identified, including 233 patients who underwent RSI. Patients who were intubated by emergency physicians had a higher median injury severity score $(P<0.001)$ and a lower median revised trauma score $(P<0.001)$. Anaesthetists had a higher proportion of successful first-attempt intubations $(P=0.034)$ but there was no difference in the rates of complications $(10 \%$ versus $10.6 \%)$.

Data from the Trauma Audit and Research Network ${ }^{18}$ indicate that, in an emergency department seeing 68000 patients per annum, 2 emergency RSIs for trauma will be required each month. In urban Scottish emergency departments the estimate is $2.5 .{ }^{19}$ Clearly, it will be difficult to maintain skills in trauma RSI through clinical exposure alone.

\section{Paediatrics}

Intubation of a child in the emergency department is fortunately a very rare event. In the USA emergency physicians appear to be as effective in performing RSI in children as in adults. ${ }^{8,20}$ However, the US data may not be immediately applicable to the UK since in that country paediatrics can go up to 18 years of age $;^{8}$ furthermore, some departments have specific paediatric emergency physicians. Oglesby et al. reviewed the data on paediatric intubation from the Scottish RSI study. ${ }^{21} 44$ children (0-12 years) were intubated in seven departments over 2 yearsless than three intubations per hospital per annum. Most intubations were performed for trauma and $68 \%$ of patients underwent RSI. In this small study, only one patient required three attempts for intubation and there were no failures. In a UK district general hospital, an anaesthetist, let alone a paediatric anaesthetist, may not be available at a time of acute need. Because these cases are so rare, trainees will not gain the necessary experience without interdisciplinary training programmes.

\section{Training courses}

The NEAR course, which offers a stepwise logical approach to the emergency airway patient, has been successfully run in the UK. ${ }^{22}$ Though excellent it may require some modification for UK purposes. The Scottish Airway and Ventilation Course (SAVE Course), developed at the Scottish Clinical Simulation Centre in Stirling Royal Infirmary, has likewise been successfully run in England. ${ }^{19}$ It is aimed at senior emergency medicine trainees and consultants who already have three to six months' experience in anaesthesia and intensive care. The course is run on a high-fidelity adult anaesthesia simulator and each 
candidate is exposed to a simulated airway emergency that requires assessment, a decision on the method to be adopted, and execution of that method if appropriate. If the correct method is selected, the simulator allows integration of physiological data and drug pharmacology in a very realistic manner. If the candidate elects to go down an alternative route, this can also be accommodated. In anaesthetists, high-fidelity anaesthesia simulators have been shown to improve both technical ${ }^{23-25}$ and non-technical skills, ${ }^{26,27}$ and the same is likely to be true of emergency physicians. The simulator may also be a valuable tool for skills maintenance.

\section{THE NEXT TEN YEARS}

A working party has been established between the Faculty of Accident and Emergency Medicine and the Royal College of Anaesthetists to plan for the future training of emergency medicine specialists in airway management. Debate continues on how emergency physicians who provide comprehensive airway care should be trained and maintain their skills. ${ }^{10,19,28-30}$ There is also debate on the training requirements for anaesthetists with respect to airway management. ${ }^{31,32}$

One proposal is that, in view of the shortage of anaesthetists in the UK, all airway interventions in the emergency department should be managed by emergency physicians. This is likely to be a minority view, since many anaesthetists are understandably reluctant to relinquish their involvement in these patients. ${ }^{22}$ In the future, as more emergency physicians are trained and become comfortable with emergency airway management, views may change in both specialties.

Ten years from now, there should be a well established UK registry of emergency department airway interventions, allowing continuous national data collection and audit of individual and departmental practice. This registry will be real-time and internet based, and will offer data on individual and departmental performance. Training will be standardized across the UK such that all emergency medicine trainees will have done twelve months of anaesthesia and critical care as basic specialist trainees. This will be integrated with a dedicated course on RSI during initial training and be followed by a SAVE-type course for the higher trainee. Emergency department consultants will be competent airway specialists and will directly supervise or perform all emergency airway interventions in their departments. They will involve anaesthetists and intensive care teams at an early stage in resuscitation and will recognize those few patients in whom airway management requires the expertise of the anaesthesia team. Consultants will be strong role models for their trainees.

Some emergency department specialists will undertake further research into aspects of airway management - for example, on the choice of induction agent and neuromuscular blocking drug, the use of operating department assistants or nurses, the application of cricoid pressure and the value of invasive haemodynamic monitoring as an aid to RSI. Within the next ten years, some of these questions will have been resolved for the benefit of future patients.

\section{REFERENCES}

1 British Association for Accident and Emergency Medicine. History of Accident \& Emergency Medicine in the UK. London, 2004. [www.baem.org.uk/hist.htm]. Accessed 15 December 2004

2 Gwinnutt CL. The interface between anaesthesia and emergency medicine. Emerg Med J 2001;18:325-6

3 McBrien ME, Pollok AJ, Steedman DJ. Advanced airway control in trauma resuscitation. Arch Emerg Med 1993;9:177-80

4 Graham CA, Meyer AD. Prehospital emergency rapid sequence induction of anaesthesia. J Accid Emerg Med 1997;14:219-21

5 Faculty of Accident \& Emergency Medicine. Higher Training in Accident \& Emergency Medicine-Secondments. London, 1999. [www.faem.org.uk/site/downloads/documents/secondmentrules01.doc]. Accessed 15 December 2004

6 Walls RM, Vissers RJ, Sagarin MJ. Emergency department intubations - final report of the National Emergency Airway Registry Pilot Project. J Accid Emerg Med 1998;15:392

7 Bair AE, Filbin MR, Kulkarni RG, Walls RM. The failed intubation attempt in the emergency department: analysis of prevalence, rescue techniques, and personnel. J Emerg Med 2002;23:131-40

8 Sagarin MJ, Chiang V, Sakles JC, et al. Rapid sequence intubation for pediatric emergency airway management. Pediatr Emerg Care 2002; 18:417-23

9 Nightingale P. Improving the care of the seriously ill patient: the interface between the accident and emergency department and critical care areas. Emerg Med J 2001;18:326-7

10 Nolan J, Clancy M. Airway management in the emergency department. Br J Anaesth 2002;88:9-11

11 Walker A, Brenchley J. Survey of the use of rapid sequence induction in the accident and emergency department. J Accid Emerg Med 2000; 17:95-7

12 Graham CA, Thakore SB, Mattick AP, Docherty E, Wares GM. Rapid sequence intubation: a survey of senior and middle grade staff in Scotland [Abstract]. J Accid Emerg Med 2000;17:71

13 Butler JM, Clancy M, Robinson N, Driscoll P. An observational survey of emergency department rapid sequence intubation. Emerg Med J 2001;18:343-8

14 Graham CA, Beard D, Oglesby A, et al. Rapid sequence intubation in Scottish urban emergency departments. Emerg Med J 2003;20:3-5

15 Schwartz DE, Matthay MA, Cohen NH. Death and other complications of emergency airway management in critically ill adults. A prospective investigation of 297 tracheal intubations. Anesthesiology 1995;82:367-76

16 Carley SD, Gwinnutt C, Butler J, Sammy I, Driscoll P. Rapid sequence induction in the emergency department: a strategy for failure. Emerg Med J 2002;19:109-13

17 Graham CA, Beard D, Henry J, McKeown DW. Rapid sequence intubation of trauma patients in Scotland. J Trauma-Injury Infect Crit Care 2004;56:1123-6

18 Butler JM, Lecky F, Townend WJ, Bouamra O, Woodford M. Intubations in trauma patients in UK emergency departments [Abstract]. Annual Scientific Meeting of the Faculty of Accident and Emergency Medicine. London, November 2001: A11

19 Graham CA. Advanced airway management in the emergency department: what are the training and skills maintenance needs for UK emergency physicians? Emerg Med J 2004;21:14-19 
20 Chiang VW, Sagarin MJ, Walls RM. Endotracheal intubations in a pediatric emergency department. Pediatr Res 1999;45:461

21 Oglesby AJ, Graham CA, Beard D, McKeown DW. Paediatric intubation in Scottish emergency departments. Paediatr Anaesth 2003;13:589-95

22 Lockey DJ, Black JJ. Emergency physicians: additional providers of emergency anaesthesia? Anaesthesia 2002;57:629-31

23 Chopra V, Engbers FH, Geerts MJ, Filet WR, Bovil JG, Spierdijk J. The Leiden anaesthesia simulator. Br J Anaesth 1994;73: 287-92

24 Chopra V, Gesink BJ, de Jong J, Bovill JG, Spierdijk J, Brand R. Does training on an anaesthesia simulator lead to improvement in performance? Br J Anaesth 1994;73:293-7

25 Forrest FC, Taylor MA, Postlethwaite K, Aspinall R. Use of a highfidelity simulator to develop testing of the technical performance of novice anaesthetists. BrJ Anaesth 2002;88:338-44
26 Fletcher G, Flin R, McGeorge P, Glavin R, Maran N, Patey R. Anaesthetists' Non-Technical Skills (ANTS): evaluation of a behavioural marker system. Br J Anaesth 2003;90:580-8

27 Fletcher GC, McGeorge P, Flin RH, Glavin RJ, Maran NJ. The role of non-technical skills in anaesthesia: a review of current literature. $\mathrm{Br} J$ Anaesth 2002;88:418-29

28 Davies G, Lockey D. Airway management in the emergency department. Br J Anaesth 2002;88:877-9

29 Graham CA, Munro PT. Airway management in the accident and emergency department. Anaesthesia 2000;55:814

30 Graham CA, Beard D, McKeown DW. Airway management in the emergency department. Br J Anaesth 2002;89:659-60

31 Stringer KR, Bajenov S, Yentis SM. Training in airway management. Anaesthesia 2002;57:956-83

32 Ball DR, Jefferson P. The airway and the anaesthetist. Anaesthesia 2001;56:693-4 